Check for updates

The BMJ

Cite this as: BMJ2020;371:m4163 http://dx.doi.org/10.1136/bmi.m4163 Published: 28 October 2020

\title{
Covid-19: Antibody prevalence in England fell from $6.0 \%$ to $4.4 \%$ over three months, study finds
}

\section{Elisabeth Mahase}

The number of people in England who tested positive for IgG antibodies against covid-19 fell by $26 \%$ from June to September, a large study of 365000 adults has found.

Results from the REACT (real time assessment of community transmission) antibody study, available as a preprint paper, ${ }^{1}$ showed that the national antibody prevalence around 12 weeks after the epidemic's April peak was 6\%. However, this had fallen to $4.8 \% 18$ weeks after the peak and at 24 weeks was $4.4 \%$.

The study, led by Imperial College London, analysed finger prick antibody tests (lateral flow immunoassay test for IgG) carried out at home from 20 June to 28 September. The tests were taken in three rounds approximately 12, 18, and 24 weeks after the early April peak, with different people asked to take part at each stage. Participants were randomly selected from the NHS patient list and sent an invitation. In total, 17576 tests were positive.

"We observe a significant decline in the proportion of the population with detectable antibodies over three rounds of national surveillance," the researchers wrote. "This is consistent with evidence that immunity to seasonal coronaviruses declines over 6 to 12 months after infection and emerging data on SARS-CoV-2 that also detected a decrease over time in antibody levels in individuals followed in longitudinal studies."

The paper reported that the patterns of infection were similar over the three rounds of the study, with prevalence highest among people aged 18-24 and lowest in those over 75 . In the most recent round of testing, the researchers noted, prevalence remained highest in London at 9.5\%, compared with $1.6 \%$ in the south west of England.

The paper reported, "People of Black (includes Black Caribbean, African and Black British) and Asian (mainly South Asian) ethnicity had higher prevalence (13.8\% [12.6-15.1] and 9.7\% [9.1-10.4]) respectively, than those of white ethnicity (3.6\% [3.5-3.8]).

Prevalence was also higher among people working in health and social (residential) care, those living in more deprived areas and larger households."

\section{Aspects of immunity}

Eleanor Riley, immunology and infectious disease professor at the University of Edinburgh, commented, "It would be premature to assume that this means that immunity to SARS-CoV-2 does not last: the study does not look at antibody concentrations, antibody function, or other aspects of immunity such as T cell immunity and does not look at the trajectory of antibody levels in the same individuals over time.
"Nevertheless, the data do lend weight to the concern that antibodies induced by natural infection may be short lived, as is the case for other seasonal coronaviruses."

Despite this, said Riley, the findings did not mean that a covid-19 vaccine would induce only short term immunity. She explained, "Vaccines contain immune stimulators-adjuvants-that induce durable immune responses, and the administration of multiple doses of vaccine ensures that high concentrations of antibodies, which decline only slowly over time, are achieved in the majority of vaccine recipients."

Meanwhile, Jonathan Ball, professor of molecular virology at the University of Nottingham, said, "Antibodies are likely to be important in protecting us from future infection and disease, but other arms of the immune system, for example cellular immunity, might also be key.

"Therefore it is essential that we gain a better understanding of what protective immunity looks like, and this can only be gleaned by measuring all aspects of immunity following infection and seeing how this relates to reinfection risk."

\section{Ward H, Cooke G, Atchison C, etal. Declining prevalence of antibody positivity to SARS-CoV-2: a community study of 365000 adults. [Preprint]2020. https://www.imperial.ac.uk/media/imperial-college/institute- of-global-health-innovation/MEDRXIV-2020-219725v1-El- liott.pdfdoi: 10.1101/2020.10.26.20219725.}

This article is made freely available for use in accordance with BMJ's website terms and conditions for the duration of the covid-19 pandemic or until otherwise determined by BMJ. You may use, download and print the article for any lawful, non-commercial purpose (including text and data mining) provided that all copyright notices and trade marks are retained. 